\title{
A relevância dos tribunais de contas no auxílio do controle externo frente à ineficiência da administração pública
}

\author{
The relevance of the courts of auditors in the aid of external control in \\ front of the inefficiency of public administration
}

Guilherme Aparecido da Silva Maia

Universidade Anhanguera-Uniderp

Diego Schlosser de SÁ Teles

Faculdade Estácio de Sá de Campo Grande (MS)

Resumo Este trabalho aborda assuntos atuais e relevantes acerca dos Tribunais de Contas e de sua indispensável participação nas atividades de controle externo. O enfoque está voltado às precariedades de toda a sistemática política e administrativa em que estão inseridas as Cortes de Contas, bem como, na importância da autonomia e independência desses Tribunais. A metodologia utilizada é preponderantemente a pesquisa bibliográfica, sem deixar de lado, todavia, a pesquisa em sítios eletrônicos que apresentam temas hodiernos e de relevante interesse público. O objetivo maior deste trabalho é demonstrar os motivos da existência e da imprescindibilidade dos Tribunais de Contas no Brasil, principalmente quando observados sob o prisma da eficiência na administração pública do país. Também visa retratar algumas deficiências do sistema político brasileiro, notadamente no âmbito dos Poder Legislativo, as quais impedem o alcance da máxima eficiência no trato da coisa pública. Neste trabalho, o conceito de eficiência foi versado em seu mais amplo sentido, não se bastando à economicidade e à celeridade na resolução dos problemas públicos, mas abrangendo, também, a moralidade e a finalidade pública.

Palavras-chave: Tribunais de Contas. Controle Externo. Administração Pública. EFICIÊNCIA.

ABSTRACT This work addresses current and relevant issues about the Courts of Accounts and their indispensable participation in external control activities. The focus is on the precariousness of the entire political and administrative system in which the Courts of Accounts are inserted, as well as on the importance of the autonomy and independence of these Courts. The methodology used is predominantly bibliographic research, without neglecting, however, research on electronic sites that present current themes and of relevant 
public interest. The main objective of this work is to demonstrate the reasons for the existence and the indispensability of the Courts of Accounts in Brazil, especially when observed from the perspective of efficiency in the public administration of the country. It also aims to portray some deficiencies in the Brazilian political system, notably in the sphere of the Legislative Branch, which prevent the achievement of maximum efficiency in dealing with public affairs. In this work, the concept of efficiency was approached in its broadest sense, not being sufficient to economy and speed in solving public problems, but also encompassing morality and public purpose.

Keywords: Courts of Accounts. External Control. Public administration. Efficiency.

\section{INTRODUÇÃo}

O presente trabalho aborda pontos específicos acerca dos Tribunais de Contas no Brasil, sobretudo no que diz respeito ao auxílio do controle externo exercido pelo Poder Legislativo. Perquirimos, ao longo de cada seção, alcançar a maior objetividade possível, sem permitir, no entanto, que os temas versados ficassem incompletos ou imprecisos.

As divisões deste artigo científico foram expostas de forma progressiva, objetivando ambientar o leitor gradualmente, iniciando-o por meio de breves introduções, passando por assuntos cada vez mais específicos, até chegarmos ao ponto crucial do trabalho, isto é, a conclusão.

A primeira seção do desenvolvimento apresenta uma sucinta introdução a respeito do surgimento da ideia de controle nas civilizações organizadas. Nela, também dissertamos sobre o conceito de "controle" elaborado pela doutrina especializada, cujos ensinamentos vêm sendo aplicados até os dias atuais. Nesta mesma seção foram expostos os objetos do controle ao qual nos referimos, como classificado pela doutrina majoritária. Elencamos, ainda, os momentos em que podem ser realizados os controles, bem como, as suas formas e os respectivos órgãos incumbidos dessa função.

Na seção seguinte, apresentamos um minucioso conceito de "controle externo", tornando evidente, também, as suas principais características. A seguir, foram brevemente exibidos os sistemas de controle externo existentes não só no Brasil, mas em diversos países.

$\mathrm{Na}$ quarta seção, buscamos fazer um paralelo demonstrando as diferenças e a relação existentes entre o Poder Legislativo e os Tribunais de Contas, objetivando salientar a importância das Cortes de Contas no país, especialmente no que diz respeito à moralidade e à eficiência da Administração Pública brasileira. Ademais, consideramos importante exteriorizar as deficiências presentes no Poder Legislativo brasileiro, as quais possuem relação direta com o sistema político vigente no país.

Na quinta e última seção do desenvolvimento, depois de apontadas as mazelas do Poder Legislativo, acentuamos a importância dos Tribunais de Contas diante da ineficiência na Administração Pública, de modo a narrar sinteticamente o trajeto e os percalços pelos quais passaram as Cortes de Contas brasileiras até chegarem ao momento presente. Nas subseções, tornamos evidentes os motivos que nos levam a enxergar as Cortes de Contas como sendo a instituição significativamente mais preparada para o efetivo exercício do 
controle externo do que o próprio Poder Legislativo. Na última subseção, tratamos de delinear o conceito de eficiência ao qual nos referimos, ilustrando e explicando o porquê da importância de garantir que os Tribunais de Contas se mantenham atualizados acerca das novas tendências tecnológicas, ambientais e políticas que vêm surgindo.

Finalmente, depois de apresentados os principais assuntos pertinentes ao tema em questão, passamos à conclusão, onde, desde já, ressaltamos estar concentrada a ideia central de todo o trabalho. Cada seção versou a respeito de objetos e assuntos autônomos dentro da matéria em discussão, de modo que todas elas pudessem ser interligadas na parte final.

O objetivo maior deste trabalho é questionar se o sistema de controle externo implantado pela Constituição Federal de 1988, especialmente no que diz respeito ao alcance da eficiência na Administração Pública, seria, de fato, o mais efetivo dos sistemas, considerando que o Poder responsável pela fiscalização externa das entidades públicas ser essencialmente político, ou seja, um Poder carente de tecnicidade, imparcialidade, e o mais grave de tudo, imerso numa engrenagem movida por interesses político-partidários e, na prática, insubordinado ao interesse público.

Quanto às referências, pelo fato de o acervo doutrinário não ser tão vasto como nos demais temas do Direito, utilizamo-nos de poucas, mas fundamentais doutrinas, no principal intuito de dar credibilidade e seguros fundamentos jurídicos acerca dos assuntos que permeiam o tema em discussão.

\section{DA ORIGEM E DAS FORMAS DE CONTROLE DA ADMINISTRAÇÃO PÚBLICA}

Não houve na história das civilizações um marco inicial específico acerca das origens do controle externo exercido sobre as contas dos governantes ou imperadores, mas sabe-se que seu surgimento decorreu de uma forte necessidade de controle dos gastos públicos, notadamente quando o excesso de riquezas nas mãos do Estado (que não eram apenas em moeda, mas também em materiais, alimentos etc.) começou a ser um problema para a administração dos impérios e dos povos organizados. Assim, buscou-se uma maneira de assegurar que os recursos captados por um governo fossem aplicados conforme as finalidades pretendidas pelos governantes.

No entendimento de Ferreira Filho (1984, p. 70), a Ciência Jurídica incluiu o poder como um dos elementos constitutivos do próprio Estado. Por essa perspectiva, o poder estatal dirige a nação a qual a ele se subordina por meio da obediência. Nesse sentido, a sociedade se organiza em torno desse poder, confirmado pelo Estado de Direito. Evidentemente, por esse prisma, legitimado está o poder fiscalizador do Estado, inclusive, em relação aos gastos públicos.

Embora o Estado tenha se consolidado ao longo da história da humanidade, a ideia de uma Corte de Contas emerge no final da Idade Média, especialmente em países como a Inglaterra, França e Espanha. Portugal criou seu Tribunal de Contas em 1849, tendo repartições em diversas cidades do Brasil Colônia (LIMA, 2015, p. 85).

Reconheceu-se, ainda, a necessidade de controle sobre os gastos públicos na Declaração dos Direitos do Homem e do Cidadão, por meio da qual as sociedades adquiriram o di- 
reito de tomar conhecimento das contas públicas geridas pelos governantes, instituindo-se, assim, o principal enfoque do controle externo, qual seja, a prestação de contas.

Na Administração Pública, o controle é decorrência direta do Estado de Direito (LOCKE, 2002, p. 94), tendo como finalidade impedir os abusos cometidos pelas autoridades públicas, fazendo isso por meio de fiscalizações, aconselhamentos, instruções, correções e, quando necessário, sanções.

Como bem colocado por Evandro Martins Guerra:

Controle, como entendemos hoje, é a fiscalização, quer dizer, inspeção, exame, acompanhamento, verificação, exercida sobre determinado alvo, de acordo com certos aspectos, visando averiguar o cumprimento do que já foi predeterminado ou evidenciar eventuais desvios com fincas de correção, decidindo acerca da regularidade ou irregularidade do ato praticado. Então, controlar é fiscalizar emitindo um juízo de valor (GUERRA, 2019, p. 90).

São por essas e outras razões que o controle é necessário dentro de qualquer governo organizado e democrático.

\section{OS OBJETOS DO CONTROLE DA ADMINISTRAÇÃo PÚbLICA}

A melhor doutrina classifica o controle, relativamente aos seus objetos, como sendo de três espécies: legalidade, mérito e gestão. A primeira espécie, legalidade, diz respeito ao controle exercido sobre os atos dos administradores públicos em seus aspectos legais e normativos, analisando se $\mathrm{o}$ ato praticado obedeceu às exigências e às formalidades dispostas na legislação.

Quanto ao controle de mérito, este se dá por meio de uma avaliação discricionária exercida pelo órgão controlador, cujos parâmetros utilizados são a oportunidade e a conveniência do ato administrativo.

Por fim, o controle de gestão busca averiguar se o ato praticado corresponde aos planos e metas de governo previamente estipulados nos orçamentos, bem como, se o ato atendeu aos critérios de economicidade, eficiência, eficácia e efetividade (CARNEIRO, 2010, p. 63).

\section{OS MOMENTOS DE REALIZAÇÃo DO CONTROLE DA ADMINISTRAÇÃo PÚBLICA}

No tocante ao tempo em que os controles podem ser realizados, existem três diferentes momentos, tendo cada um deles características e finalidades diversas, quais sejam: prévio (ex-ante), concomitante (pari-passu) e subsequente (a posteriori).

O controle prévio é, na maioria das vezes, exercido pelas auditorias internas ou corregedorias integrantes do próprio órgão fiscalizado, tendo por finalidade antever, prevenir e corrigir eventuais irregularidades que poderiam macular todo o procedimento administrativo. Controle concomitante é aquele exercido no momento em que os atos estão sendo praticados, sendo iniciado, geralmente, por provocação dos órgãos ou entidades responsáveis 
pela fiscalização, tais como as corregedorias, o Ministério Público ou até mesmo os Tribunais de Contas. Enfim, o controle subsequente é normalmente realizado pelos Tribunais de Contas, e recai sobre os atos já finalizados, a exemplo das prestações de contas anuais dos chefes de cada Poder, possuindo caráter corretivo e, por vezes, sancionatório.

\section{AS FORMAS DE CONTROLE E OS RESPECTIVOS ÓRGÃOS CONTROLADORES}

O controle exercido sobre o Poder Executivo, na sua função administrativa, se expressa de duas formas distintas: interna e externamente. O primeiro é assim chamado porque se materializa no interior do próprio órgão, entidade ou Poder, uma vez que o agente controlador integra a própria pessoa jurídica controlada. No entanto, a responsabilidade pelo controle exercido externamente se efetiva sob três diferentes aspectos: jurisdicional, político e técnico (ALBUQUERQUE, 2010, p. 93).

Os órgãos do Poder Judiciário (estadual e federal) são responsáveis pelo controle jurisdicional, garantindo a legalidade e a constitucionalidade dos atos praticados pela Administração Pública, sendo respaldados pelo o artigo $5^{\circ}$., inciso XXXV, da Constituição Federal, o qual determina a inafastabilidade da tutela jurisdicional de ato lesivo ou atentatório a direito.

O controle político, por sua vez, incumbe aos órgãos do Poder Legislativo, cujas competências estão previstas no Capítulo I do Título IV da Constituição Federal, lhes sendo permitida a utilização de instrumentos como as Comissões Parlamentares de Inquérito CPIs, convocações de autoridades públicas para prestarem esclarecimentos, como sustações de atos do Poder Executivo que excedam do poder regulamentar ou os limites de delegação legislativa.

Relativamente ao controle técnico, são competentes para tanto os Tribunais de Contas, em auxílio ao Poder Legislativo, assim como os órgãos responsáveis pelo controle interno nas três esferas de cada Poder (municipal, estadual e federal), cujas atribuições e características já foram mencionadas.

\section{O CONTROLE EXTERNO DA ADMINISTRAÇÃO PÚBLICA}

Restando brevemente compreendido o que se entende por controle e como este surgiu nas sociedades, torna-se possível adentrar no estudo do controle externo propriamente dito. O entendimento desses dois assuntos é, sem dúvida, fundamental à compreensão dos tópicos que serão abordados a seguir e indispensável à contextualização do tema geral deste trabalho com o momento atual vivido no Brasil.

Assim como na maioria dos conceitos propostos pela doutrina, também há no caso do controle externo tênues divergências doutrinárias, no entanto, em respeito à objetividade e à lucidez deste trabalho, será apresentado a seguir um único, mas analítico, conceito de controle externo.

Consoante leciona Frederico Pardini:

Controle externo sobre as atividades da Administração, em sentido orgânico e 
técnico, é, em resumo, todo controle exercido por um Poder ou órgão sobre a administração de outros. Nesse sentido, é controle externo o que o judiciário efetua sobre os atos dos demais Poderes. É controle externo o que a administração direta realiza sobre as entidades da administração indireta. É controle externo o que o Legislativo exerce sobre a administração direta e indireta dos demais Poderes. Na terminologia adotada pela Constituição, apenas este último é que recebe a denominação jurídico-constitucional de controle externo (CF arts. 31 e 70 a 74), denominação esta repetida especificamente em outros textos infraconstitucionais, como, por exemplo, a Lei no. 8.443/1992 (PARDINI, 2004, p. 40).

Nesse sentido, o mesmo autor minudencia quais são as características essenciais do controle externo:

a) é externo porque é exercido pelo Parlamento sobre a administração pública direta e indireta e sobre as atividades de particulares que venham a ocasionar perda, extravio ou dano ao patrimônio público [...]

b) é controle porque lhe compete examinar, de forma mais ampla possível, a correção e a regularidade e a consonância dos atos de Administração com a lei e com os planos e programas;

c) é múltiplo, pois examina, simultaneamente, a legalidade, a legitimidade e a economicidade dos atos que lhe compete controlar;

d) tem múltiplas incidências, pois são submetidos ao controle externo os aspectos contábil, financeiro, orçamentário, operacional e patrimonial;

e) atua em momentos diversos. Embora a regra geral seja a do controle posterior, pode, também, ser prévio, concomitante ou misto;

f) efetua-se por dois órgãos distintos e autônomos: o Parlamento e o Tribunal de Contas; [...]

\section{SiSTEMAS DE CONTROLE EXTERNO DA ADMINISTRAÇÃo PÚBLICA}

Doutrinariamente, identificam-se dois sistemas majoritariamente utilizados em diversos países do mundo, em que pese cada Estado apresentar especificidades únicas acerca da cultura, história, religião, política e administração, sendo eles o sistema de Auditorias Gerais e o sistema de Corte de Contas (ZYMLER, 2012, p. 167-168). Embora sejam sistemas diferentes, eles se assemelham em alguns aspectos marcantes, por exemplo, no fato de ambos possuírem, quase sempre, previsão constitucional, onde lhes é atribuída a missão precípua de exercer o controle externo. Ademais, ambos constituem partes integrantes do Estado e têm alto grau de independência e autonomia, não obstante possam estar vinculados aos órgãos legislativos.

No sistema de Auditorias Gerais, também conhecidas como Controladorias Gerais, as decisões são tomadas monocraticamente por Auditores ou Controladores, os quais são eleitos pelo Parlamento para um mandato previamente fixado, de modo que tais decisões não possuem caráter jurisdicional ou coercitivo, mas tão-somente opinativo, sendo exaradas por meio de recomendações e pareceres. Portanto, trata-se de órgãos auxiliares meramente opinativos, não sendo dotados de poderes para aplicar penalidades às entidades ou autoridades fiscalizadas, uma vez que essa incumbência recai ao Parlamento. 
Quanto ao sistema de Corte de Contas, as decisões são proferidas de forma colegiada, como ocorre nos Tribunais de Justiças, sendo que, em alguns países, seus membros são dotados de vitaliciedade, enquanto que em outros, são indicados ou eleitos para um mandato prefixado. Outra diferença em relação às Corregedorias diz respeito ao caráter coercitivo e jurisdicional das decisões, sendo que as Cortes de Contas possuem competência para aplicar sanções administrativas às autoridades fiscalizadas em caso de irregularidades, ou ainda competência para determinar que sejam feitas as correções devidas.

Assim, pelo fato de essas Cortes de Contas serem competentes para aplicar sanções aos jurisdicionados, notadamente quando se fala de penalidades pecuniárias ou até mesmo capazes de acarretarem sanções penais, impõe-se a elas o dever de observar com muito mais rigor todas as formalidades concernentes ao devido processo legal, especialmente no tocante ao direito do contraditório e da ampla defesa, sem os quais um processo poderia ser declarado nulo, gerando a invalidade de todos os atos praticados sem a observância dessa norma constitucional.

O sistema de Auditorias Gerais é utilizado pela grande maioria dos países, como a Argentina, África do Sul, Austrália, Canadá, Colômbia, Cuba, Estados Unidos, Índia, Jordânia, Paraguai, Suécia. São exemplos de países que adotam o sistema de Corte de Contas a Alemanha, Brasil, Coreia, Espanha, França, Grécia, Holanda, Japão, Portugal e Uruguai (LIMA, 2015, p. 42).

\section{O Poder Legislativo e os Tribunais de Contas}

Baseando-se na obra "Política", de Aristóteles (1986), bem como, na obra "Segundo Tratado sobre o Governo", de Locke (2002), o pensador francês Charles-Louis de Secondat, Baron de Montesquieu, desenvolveu o sistema Checks and Balances, também denominado de Freios e Contrapesos, o qual ficou conhecido por meio da obra "O Espírito das leis" (MONTESQUIEU, 1996). Por meio desse sistema, pretendeu-se criar um mecanismo onde os Poderes convivessem harmonicamente equilibrados, de modo que cada um pudesse impor limites a eventuais excessos cometidos pelos demais.

Nesse sistema, nos moldes adotados pela Constituição da República de 1988 (BRASIL, 2012), o controle externo tornou-se um instrumento essencial à manutenção do equilíbrio de cada Poder, tendo em vista que o âmbito de sua fiscalização é bastante vasto, incidindo sobre os aspectos contábil, financeiro, orçamentário, operacional e patrimonial, consoante o disposto no seu artigo 70, caput. Ele é chamado de externo porque se aperfeiçoa fora do Poder que administra a coisa pública, de modo autônomo e independente, sendo exercido pelo Poder Legislativo com o auxílio dos Tribunais de Contas, sendo que a incumbência de administrar os recursos públicos do Estado recai, precipuamente, ao Poder Executivo.

Por sua vez, além do controle externo, dentro de cada Poder funciona o denominado controle interno, ficando responsável pela avaliação e fiscalização eminentemente preventiva dos atos praticados pelo próprio órgão ou Poder, de modo a evitar e a corrigir eventuais irregularidades e ilegalidades, cuja competência, no âmbito do Poder Executivo Federal, recai atualmente sobre a Controladoria Geral da União - CGU. 
O artigo 74 da Constituição Federal (BRASIL, 2012) estabelece que o sistema de controle interno seja realizado de forma integrada pelos Poderes Legislativo, Executivo e Judiciário, no intuito de promover uma interação entre o controle que cada um exerce sobre sua execução orçamentária. Ele tem como objetivos avaliar o cumprimento das metas estabelecidas no plano plurianual, a execução dos programas de governo, bem como, dos orçamentos da União no âmbito de cada Poder. Ademais, busca averiguar a legalidade dos atos administrativos e avaliar a eficácia e a eficiência da gestão patrimonial, orçamentária e financeira de seus órgãos e entidades, sem esquecer-se da importante função de prestar apoio ao controle externo no exercício de sua missão institucional (CARNEIRO, 2010, p. 64).

Desse modo, fica evidente a importante tarefa que a Carta Magna de 1988 atribuiu aos controles interno e externo, sem os quais os administradores do Estado incorreriam livremente em inúmeras falhas, ilegalidades e imoralidades capazes de desestruturar todo o sistema republicano brasileiro, tendo em vista que essa forma de governo é nada menos que uma confirmação de que o patrimônio do governo, na verdade, é um patrimônio público, e que por esse motivo não se admite que sua administração caminhe de maneira deficitária, ineficiente e imoral.

\section{A RelaÇÃo ENTRE OS TRIbUNAIS DE CONTAS E O PODER LEGISLATIVO}

De modo diferente do que ocorre na maioria dos países, a Constituição portuguesa possui uma relevante peculiaridade, tendo em vista que o seu Título V, que trata dos Tribunais, aloca o Tribunal de Contas, no artigo 214, na esfera do Poder Judiciário, como sendo "o órgão supremo de fiscalização da legalidade das despesas públicas e de julgamento das contas que a lei mandar submeter-lhe" (PORTUGAL, 2005). Na Grécia, do mesmo modo, o Tribunal de Contas é parte integrante do Poder Judiciário, demonstrando a relevância atribuída aos atos de fiscalização e julgamento dos gastos públicos nesses países.

Em Cuba, no entanto, o Tribunal de Contas perdurou apenas de 1952 a 1960, tendo sido extinto pela Lei Fundamental da Revolução Cubana, que o acusou de não cumprir suas obrigações e de ter as mais importantes autoridades envolvidas em crimes de corrupção. Dessa forma, no ano seguinte à sua extinção, foi aprovada a Lei de Comprovação dos Gastos do Estado, a qual deu origem à criação do Ministério de Auditoria e Controle, ficando esse órgão de fiscalização alocado na esfera do Poder Executivo (LIMA, 2015, p. 41).

Em contrapartida, no Brasil, o Tribunal de Contas da União é composto por nove ministros de nacionalidade brasileira, cada um deles com mais de 35 e menos de 65 anos de idade, que possuem idoneidade moral e reputação ilibada, com notórios conhecimentos jurídicos, contábeis, econômicos e financeiros ou de administração pública, e que tenham mais de dez anos de exercício de função ou de efetiva atividade profissional em algumas das mencionadas áreas de conhecimento (art. $73, \S 1^{\circ}$., incisos I a IV).

Ademais, é uma entidade dotada de autonomia institucional, com administração e funcionalismo próprios, cujos atos praticados são de natureza estritamente administrativa, ou seja, não é órgão integrante do Poder Judiciário, portanto, não exerce "jurisdição", muito embora o artigo 73, caput, da Constituição Federal tenha se utilizado desse termo para definir a abrangência de suas decisões. 
Nesse mesmo sentido, leciona Pedro Lenza:

\begin{abstract}
Malgrado tenha o art. 73 da CF falado em "jurisdição" do Tribunal de Contas, devemos alertar que essa denominação está totalmente equivocada. Isso porque o Tribunal de Contas é órgão técnico que, além de emitir pareceres, exerce outras atribuições de fiscalização, de controle e, de fato, também a de "julgamento" (tanto é que o Min. Ayres Britto chega a falar em "judicatura de contas" - ADI 4.190) (BRASIL, 2010, p. 357). Porém, o Tribunal de Contas não exerce jurisdição no sentido próprio da palavra, na medida em que inexiste a "definitividade jurisdicional". É por esse motivo que reputamos não adequada a expressão "jurisdição" contida no art. 73 (LENZA, 2015, p. 743).
\end{abstract}

Assim, pode-se dizer que as Cortes de Contas são órgãos técnicos, dotados de competências administrativas, destinados a emitir pareceres sobre as contas públicas dos três Poderes, bem como, julgar as contas de todos aqueles que utilizam, guardam, arrecadam, administram, gerenciam dinheiro, bens ou valores públicos pelos quais o Estado responda (art. 70, parágrafo único). Além disso, são órgãos que não integram nem o Poder Judiciário, nem o Legislativo, muito menos o Executivo, possuindo, entretanto, vínculo com o Poder Legislativo, no sentido de que exerce com este o auxílio do controle externo, que de modo algum pode ser confundido com uma relação de subordinação, hierarquia ou delegação de competências.

Por fim e para melhor elucidar o contexto em que estão inseridos os Tribunais de Contas no Brasil, o ministro Celso de Mello explanou seu entendimento no seguinte sentido:

Os Tribunais de Contas ostentam posição eminente na estrutura constitucional brasileira, não se achando subordinados, por qualquer vínculo de ordem hierárquica, ao Poder Legislativo, de que não são órgãos delegatários nem organismos de mero assessoramento técnico. A competência institucional dos Tribunais de Contas não deriva, por isso mesmo, de delegação dos órgãos do Poder Legislativo, mas traduz emanação que resulta, primariamente, da própria Constituição da República (ADI 4.190, j. 10.03.2010).

\title{
9. As mazelas do Poder Legislativo no controle da administração PÚBLICA BRASILEIRA
}

Tomado conhecimento de que o controle externo é indispensável à forma republicana de governo, façamos, então, uma análise crítica acerca do Poder Legislativo, o qual é detentor desse controle, mantendo o enfoque nas inconsistências que podem retardar a eficiência da administração pública e até mesmo colocar em risco o regime democrático brasileiro (MEIRELLES, 2016, p. 119).

Além da função primária de legislar, a Constituição Federal Brasileira de 1988 designou o Poder Legislativo para desempenhar a função fiscalizatória, atribuindo-lhe competência para exercer o controle externo da União, dos Estados, dos Municípios, do Distrito Federal e das entidades integrantes de suas administrações direta e indireta, observado o âmbito de atuação das respectivas casas legislativas. Essa fiscalização recai sobre os aspec- 
tos da legalidade, legitimidade, economicidade, aplicação das subvenções e renúncia de receitas (art. 70, caput).

É importante notar a responsabilidade política do Poder Legislativo, de representar a vontade do povo, assim como também sua responsabilidade como poder fiscalizador. Essa função é reconhecida pelos países desenvolvidos, como a Inglaterra, por exemplo, que desde a Magna Carta de 1215 vem estruturando um Estado com forte poder fiscalizador. Essa linha de ação governamental tem se fundado em um "vigoroso instrumento de controle sobre as políticas adotadas pelo Executivo e sobre suas atividades, na medida em que incide sobre aportes e despesas públicas" (CAGGIANO, 2004, p. 21).

Para a autora, a força fiscalizadora do legislativo, tem raízes no poder econômico do Estado, fruto de sua função tributária, pois, ao receber do Estado de Direito a função de arrecadar recursos para a manutenção do Estado, na sua função administrativa de garantir bens e produtos à sociedade, recai sobre ele, Estado, a responsabilidade no trato responsável desses recursos.

No Brasil, a fiscalização dos gastos públicos também recai sobre o Poder Legislativo (instância política), com a ajuda do Tribunal de Contas, no entendimento de Castardo (2007, p. 74), instituição independente, com fundamento técnico, cuja missão é fiscalizar a aplicação dos recursos públicos, conforme previamente previsto no orçamento público.

Entretanto, de modo diferente do que ocorre nos Tribunais de Contas, no Poder Legislativo seus membros são eleitos pelo voto da maioria, tornando-se os representantes do povo por excelência. Apesar disso, tais representantes são majoritariamente leigos em relação às atividades técnicas realizadas pelo Estado, isso porque a nossa Lei Maior não impõe a exigência de qualquer conhecimento técnico ou jurídico para ser diplomado num cargo político, contanto que sejam preenchidos os requisitos mínimos de idade para cada cargo e que não se incorra em qualquer dos impedimentos legais (MEIRELLES, 2016, p. 120).

Além disso, é notório que a grande maioria dos cidadãos brasileiros culturalmente não escolhe seus candidatos utilizando pesquisas objetivas e ilibadas que demonstrem o grau de aptidão técnica dos pretensos políticos, mas forma sua opinião baseando-se por questões meramente ideológicas e partidárias, deslembrando-se de avaliar nos candidatos a capacitação mínima exigida para um bom desempenho das funções públicas.

Embora a maioria dos cidadãos acredite que a um parlamentar incumbe apenas proferir votos e manifestar opiniões nas casas legislativas, suas funções vão (ou deveriam ir) muito além do senso comum. O pleno conhecimento de toda a sistemática acerca do ordenamento jurídico brasileiro, dos princípios e garantias constitucionais, das questões administrativas e tributárias, dos orçamentos públicos, das finanças públicas, da complexa estruturação e das competências de cada Poder, enfim, a compreensão geral acerca das matérias ligadas à Administração Pública certamente ultrapassa o conhecimento comum do povo, mas que não deixa de ser imprescindível ao cumprimento das atribuições públicas, notadamente quando se tratam de agentes políticos incumbidos de elaborar normas que surtirão efeitos em todo o país e para todos os cidadãos.

No entanto, sistemas como esse são utilizados em quaisquer governos democráticos, onde, em tese, prevalece a vontade da maioria, especialmente porque há investimentos estratosféricos dos grandes partidos políticos em épocas de eleição, de modo a influen- 
ciar significativamente a maior parte da população que sequer conhece a organização básica do Estado.

Além das incorreções existentes ao longo do processo eleitoral, ao serem investidos nos cargos políticos, muitos parlamentares não conseguem (outros não querem) atuar com a pura e simples finalidade para a qual foram eleitos, porquanto se deparam com um complexo e obscuro sistema de negociações políticas dentro das próprias casas legislativas, onde, em muitas das vezes, se veem obrigados a satisfazer os interesses político-partidários em detrimento do interesse público.

Por consequência, em âmbito federal, deparamo-nos com um imenso Poder Legislativo integrado por até 513 deputados e 81 senadores, onde cada um deles recebe mensalmente, além das remunerações, verbas de gabinete para pagar até 25 secretários parlamentares de sua escolha, Cotas para o Exercício de Atividades Parlamentares (CEAP) para custear despesas como passagens aéreas e contas de celular, imóveis funcionais, auxílio-moradia, diárias para viagens, entre outras vantagens (BRASIL, 2020). No entanto, apesar de auferirem todos esses benefícios que lhes deveriam garantir poder e autonomia, muitos deles ficam maculados ou limitados pelo próprio sistema político, cujas ações tendem a beneficiar uma pequena classe ou grupo específico de eleitores, afastando-se da vontade da maioria, isto é, do próprio conceito de democracia.

Diante de tudo isso, há de se questionar como seria possível para o Estado brasileiro alcançar a máxima eficiência e economicidade da máquina pública, ainda que seus maiores representantes não possuam aptidões técnicas e conhecimentos jurídicos suficientes para fiscalizá-la ou, até mesmo, administrá-la. Ademais, indaga-se até onde iria a liberdade e a independência dos parlamentares para atuarem conforme o interesse único e exclusivamente público, sem que caíssem na tentação de atenderem aos próprios interesses ou aos interesses político-partidários de seus semelhantes.

\section{A FUNÇÃo ESSENCIAL doS TRIBUNAIS DE CONTAS}

Apontadas as imperfeições e limitações que desde o início da República assolam o Poder Legislativo brasileiro, passa-se a questionar como seria possível que a Administração Pública, em especial o Poder Executivo, atue com integridade moral e com zelo à coisa pública, visto que o próprio Poder incumbido de fiscalizá-lo não detém vocação, perícia, tampouco idoneidade para julgar os gestores públicos com imparcialidade e respaldando-se em fatores técnicos em vez de fatores políticos.

Antes de qualquer coisa, porém, faz-se necessário adentrar em um diminuto estudo acerca da história e do surgimento dos Tribunais de Contas no Brasil, considerando os principais percalços pelos quais passou essa instituição até que fosse efetivamente instalada no país.

O controle é pressuposto basilar de qualquer democracia. Aristóteles, na obra "Política" (ARISTÓTELES, 1986), sustentou a necessidade de prestação de contas quanto à aplicação dos recursos públicos e de punição para responsáveis por fraudes ou desvios e defendeu a existência de um tribunal dedicado às contas e gastos públicos (MEIRELLES, 2016, p. 121). 
Os primeiros indícios acerca da existência de uma entidade responsável pela fiscalização das contas públicas no Brasil permeiam o século XIX, tendo-se materializado com a instituição do Erário Régio, também denominado de Tesouro Geral ou, ainda, Real Erário, por ato do Príncipe Regente, Dom João VI. A ideia da criação de um Tribunal de Contas no Brasil, com o debate sobre a abolição da escravidão, sofreu dura oposição e polêmica à época em que fora proposto, tendo tramitado por vários anos no Legislativo brasileiro, de modo a ser efetivamente instituída somente depois de ser proclamada a República (LIMA, 2015, p. 44).

Esses entraves criados pelos governantes para a criação de um Tribunal de natureza fiscalizatória demonstram a preocupação que existia por parte das autoridades públicas de terem suas atividades policiadas por um órgão independente e completamente autônomo, fora do alcance de seus poderes.

\section{O INÍ́CIO DOS TRIBUNAIS DE CONTAS NO BRASIL}

No Brasil, o paradigmático Decreto n. 966-A, de 7 de novembro de 1890, assinado pelo então ministro da Fazenda do Governo Provisório, instituiu um "Tribunal de Contas para o exame, revisão e julgamento dos atos concernentes à receita e despesas da República". Em seu artigo $1^{\circ}$., ficou consignado o seguinte: "É instituído um Tribunal de Contas, ao qual incumbirá o exame, a revisão e o julgamento de todas as operações concernentes à receita e a despesa da República". No seu artigo $2^{\circ}$., estipulou-se que: "Todos os decretos do Poder Executivo, ordens ou avisos dos diferentes Ministérios, susceptíveis de criar despesa, ou interessar as finanças da República, para poderem ter publicidade e execução, serão sujeitos primeiro ao Tribunal de Contas, que os registrará, pondo-lhes o seu 'visto', quando reconheça que não violam disposições de lei, nem excedam os créditos votados pelo Poder Legislativo" (BRASIL, 1890).

Com tamanha importância atribuída às Cortes de Contas, acabou-se por gerar intensos conflitos entre essa instituição de fiscalização e as autoridades fiscalizadas por elas. Quando houve a efetiva instalação dos Tribunais de Contas no Brasil, ocorrida especificamente no ano de 1893, sob o comando do então ministro da Fazenda Serzedello Corrêa, o presidente da época, Floriano Peixoto, ao ter a nomeação de um parente do ex-presidente Deodoro da Fonseca julgado como ilegal pela Corte de Contas, prontamente determinou que fossem editados diversos decretos no intuito de remover importantes competências desses Tribunais. O ministro Serzedello Corrêa, todavia, opondo-se frontalmente a essa ordem, anunciou sua demissão e, em memorável declaração, afirmou:

Esses decretos anulam o Tribunal, o reduzem a simples Ministério da Fazenda, tiram-lhe toda a independência e autonomia, deturpam os fins da instituição, e permitirão ao Governo a prática de todos os abusos e vós o sabeis - é preciso antes de tudo legislar para o futuro. Se a função do Tribunal no espírito da Constituição é apenas a de liquidar as contas e verificar a sua legalidade depois de feitas, o que eu contesto, eu vos declaro que esse Tribunal é mais um meio de aumentar o funcionalismo, de avolumar a despesa, sem vantagens para a moralidade da administração. Se, porém, ele é um Tribunal de exação como já o 
queria Alves Branco e como têm a Itália e a França, precisamos resignarmo-nos a não gastar senão o que for autorizado em lei e gastar sempre bem, pois para os casos urgentes a lei estabelece o recurso. Os governos nobilitam-se, Marechal, obedecendo a essa soberania suprema da lei e só dentro dela mantêm-se e são verdadeiramente independentes. Pelo que venho a expor, não posso, pois Marechal, concordar e menos referendar os decretos a que acima me refiro e por isso rogo vos digneis de conceder-me a exoneração do cargo de Ministro da Fazenda, indicando-me sucessor (EXPOENTES NA HISTÓRIA DO BRASIL, 1932, p. 82-83).

Aliás, percebe-se que as Cortes de Contas, àquela época, foram criadas com o escopo de exercer o controle prévio sobre praticamente todos os atos dos Chefes do Poder Executivo, os quais não poderiam realizar quaisquer ações que fossem capazes de gerar aumento de despesas sem que tivessem o aval dos Tribunais de Contas. Assim, de modo diferente do que acontece hodiernamente no Brasil, o momento de fiscalização se perfazia de modo eminentemente prévio, antes mesmo de os atos do Executivo gerar efeitos.

Essa diferença quanto ao momento de realização da fiscalização, em contraste com o que ocorre atualmente nas Cortes de Contas, corrobora com a ideia de que esses Tribunais eram e ainda são indispensáveis à manutenção do equilíbrio econômico-financeiro do país, especialmente quando se pensa nas situações deficitárias pelas quais passou o Brasil, onde a dívida externa chegou a alcançar estratosféricos 1,7 trilhões de reais no ano de 2010 (MARTELLO, 2011).

Da mesma forma, é possível notar que àquela época as Cortes de Contas eram as figuras principais no que dizia respeito ao controle das contas públicas, de modo que o julgamento do Chefe do Poder Executivo era realizado, não pelo Parlamento, mas pela própria Corte de Contas, quando o assunto era receitas e despesas públicas. Assim, a possibilidade de o presidente da República se eximir de sanções por atos que causassem prejuízos ao erário era mínima, haja vista que ele não era julgado por um órgão composto por políticos eleitos, como o Parlamento, mas sim por um órgão técnico, autônomo e sem qualquer vínculo político-partidário com os demais Poderes.

Ruy Barbosa, ao discorrer sobre o papel dos Tribunais de Contas na obra "Rui Barbosa, uma visão do controle do dinheiro público", apresentou a famosa e magnífica exposição de motivos acerca dessa instituição:

[...] corpo de magistratura intermediário à administração e à legislatura, que, colocado em posição autônoma, com atribuições de revisão e julgamento, cercado de garantias contra quaisquer ameaças, possa exercer as suas funções vitais no organismo constitucional, sem risco de converter-se em instituição de ornato aparatoso e inútil. [...] Convém levantar, entre o poder que autoriza periodicamente a despesa e o poder que quotidianamente a executa, um mediador independente, auxiliar de um e de outro, que, comunicando com a legislatura, e intervindo na administração, seja não só o vigia, como a mão forte da primeira sobre a segunda, obstando a perpetração das infrações orçamentárias, por um veto oportuno aos atos do executivo, que direta ou indireta, próxima ou remotamente, discrepem da linha rigorosa das leis de finanças. [...] Nada teremos feito, em tão melindroso assunto, o de mais alto interesse, entre todos, para o nosso futuro, enquanto não erguermos a sentinela dessa magistratura especial, envolta 
nas maiores garantias de honorabilidade, ao pé de cada abuso, de cada germe ou possibilidade eventual dele (BRASIL/TCU, 2000, p. 51).

Diante de tudo isso, faz-se possível notar a elevada importância que os Tribunais de Contas tiveram na história da construção da República Federativa do Brasil, que apesar de todas as intempéries e perseguições políticas pelas quais passou a instituição, hoje se mostra, a bem da verdade, como sendo não apenas o pilar de sustentação que mantém em equilíbrio as contas públicas do país, mas também o "grande irmão" do próprio governo, sobre o qual exerce a indispensável função de manter os olhos abertos para todo e qualquer ato que se desvie da legalidade, da economicidade, da moralidade e da finalidade pública.

\section{A insuficiência do Poder Legislativo no exercício do controle EXTERNO QUANDO COMPARADO AOS TRIBUNAIS DE CONTAS}

A primeira e, talvez, a mais importante questão a ser levantada nesta seção diz respeito ao sistema político no qual estão inseridos os Poderes Legislativo e Executivo. O vínculo político que liga um Poder ao outro é, na maioria das vezes, inimigo do sistema de Controle Externo, no sentido de que o Legislativo, ao exercer o julgamento das contas e dos demais atos praticados pelos Chefes do Poder Executivo, pode desviar-se da finalidade essencialmente pública e isentar aqueles administradores de eventuais irregularidades e ilegalidades por eles cometidas, com o propósito de atender aos interesses político-partidários que lhes sejam mais vantajosos.

Em outras palavras, a liberdade que têm os parlamentares de elaborarem negociações políticas com os Chefes de Governo é quase sempre utilizada como um verdadeiro mecanismo de troca de favores, onde a finalidade preponderante é auferir benefícios aos próprios negociadores. Trata-se de uma legítima engrenagem que movimenta as propostas legislativas e sem a qual não haveria meios para que os Chefes do Executivo alcançassem as metas e objetivos estabelecidos nos planos de governo.

Essa é a verdadeira Teoria dos Freios e Contrapesos aplicada na prática, cujo propósito seria o de equilibrar os três Poderes por meio da independência e da harmonia existentes entre si, todavia, aparentemente acabam interpretando o conceito de "harmonia entre os Poderes" como sendo sinônimo de "trocas de favores entre os Poderes".

A outra questão primordial está relacionada aos limites legais do Poder Legislativo para atuar com imparcialidade e eficiência no exercício do Controle Externo. Para ser mais exato, não se trata de ausência de capacidade técnica, mas sim de um desinteresse em fiscalizar e julgar as contas de governo baseando-se em critérios técnicos e objetivos. Como já dito, prevalecem os interesses político-partidários.

De modo diferente do Poder Legislativo, os Tribunais de Contas dos Estados são integrados por Conselheiros e, o Tribunal de Contas da União, por Ministros, os quais não são eleitos ou indicados à revelia de quaisquer pressupostos mínimos exigidos para os cargos, mas sim por possuírem notórios conhecimentos nas áreas jurídicas, contábeis, econômicas, financeiras ou de administração pública (art. $73, \S 1^{\circ}$., III da CF). 
Inclusive, os membros do Tribunal de Contas da União são guarnecidos pelas mesmas garantias, prerrogativas, impedimentos, vencimentos e vantagens dos Ministros do Superior Tribunal de Justiça (Art. 73, $\S 3^{\circ}$. da CF). Os Conselheiros dos Tribunais de Contas dos Estados, por sua vez, possuem garantias, prerrogativas, impedimentos e vantagens que se equiparam às dos Desembargadores dos Tribunais de Justiça, conforme já pacificado pela jurisprudência do Supremo Tribunal Federal (ADI 4.190,j. 10.03.2010). Entre as garantias de maior importância estão a vitaliciedade, a inamovibilidade, salvo por interesse público, e a irredutibilidade de vencimentos.

Além disso, os Tribunais de Contas possuem autonomia institucional, administrativa, financeira e organizacional, inexistindo qualquer vínculo de subordinação hierárquica com o Legislativo ou com qualquer Poder do Estado Brasileiro.

Todo esse aparato institucional corrobora com o entendimento de que os Tribunais de Contas, embora sejam classificados como meros órgãos auxiliares, são indubitavelmente mais aptos, competentes e "politicamente livres" para o efetivo exercício do controle externo do que o próprio detentor desse controle, qual seja, o Poder Legislativo.

\section{Os TRIBUNAIS de CONTAS E A EFICIÊNCIA dA ADMINISTRAÇÃo PÚBliCA BRASILEIRA}

Preliminarmente, cumpre aqui esclarecer que "eficiência" será abordada em seu mais amplo sentido, não se limitando aos aspectos da economicidade e produtividade, mas também levando em consideração as questões que dizem respeito à transparência, legalidade, impessoalidade, moralidade e, sobretudo, finalidade pública.

O conceito de eficiência ora em discussão compreende todo e qualquer aspecto da Administração Pública que esteja ligado ao interesse púbico, à finalidade pública em essência. Sob esse ponto de vista, ao se avaliar um ato de governo ou um ato de gestão, não se pode dizer que eles são eficientes quando simplesmente se aperfeiçoam com economicidade e rapidez, porquanto, se os efeitos por eles gerados não tiverem atingido a finalidade pública, isto é, alcançado o real interesse da sociedade, não se pode afirmar que tais atos foram eficientes.

Em suma, no âmbito da Administração Pública, um ato não é eficiente quando simplesmente se finaliza com baixos custos e de maneira ágil, e sim quando a sua agilidade e economicidade tiveram como meta o interesse público. Do contrário, os atos públicos seriam interpretados como sendo meras ações com um fim em si mesmas, sem qualquer pretensão a não ser a de simplesmente chegar ao fim de modo econômico e apressado.

Compreendida a ideia de eficiência explanada por este trabalho, passa-se a retratar o atual cenário em que se encontram os Tribunais de Contas, discorrendo acerca dos desafios e das dificuldades que circundam a atividade de controle externo.

A velocidade em que correm as informações na era digital é algo que certamente influencia a forma e os meios pelos quais se efetiva o exercício do controle externo, de modo que as instituições de fiscalização devem acompanhar e se adaptar a esse processo evolutivo com a mesma velocidade, sob o risco de se tornar obsoleto. Diante desse cenário, as Cortes de Contas devem se desapegar dos rituais puramente burocráticos e formalísticos 
e priorizar o alcance de finalidade pública, isso porque nas sociedades democráticas como a do Brasil aumenta-se cada vez mais a pressão popular por transparência e agilidade na atividade estatal. Do mesmo modo e com bastante intensidade, crescem as exigências populares ao Parlamento e às instituições de fiscalização e julgamento.

Com a globalização, o avanço da ciência e da tecnologia é pressuposto fundamental para que qualquer instituição pública ou privada atinja sua finalidade com presteza e efetividade, sendo indispensável que haja dentro de cada uma delas boas ferramentas de tecnologia da informação. A complexidade é inerente a qualquer atividade de controle externo, especialmente quando a fiscalização recai sobre agências reguladoras e executivas, organizações sociais, organizações da sociedade civil de interesse público, contratos de gestão e concessões de serviços públicos.

Além disso, as mudanças climáticas do planeta se apresentam como outros grandes desafios do nosso país, os quais exigem da Administração Pública uma gestão de recursos naturais inteligente, com foco na preservação dos patrimônios hídricos e da diversidade biológica, haja vista que estes são patrimônios públicos que interessam não apenas ao povo brasileiro, mas a todos os que vivem neste planeta.

O combate à corrupção é outra questão de notável importância no Brasil. Com o fim da Comissão Parlamentar Mista de Inquérito da Empresa de Correios e Telégrafos, ocorrida em 2006, diversas propostas surgiram para fortalecer as instituições que combatem a corrupção, cujo principal intuito era de instalar um sistema de controle a nível nacional, que envolveria os Tribunais de Contas estaduais e municipais, o controle interno, a Polícia Federal, a Receita Federal, o Banco Central, entre outras, tendo como coordenador o Tribunal de Contas da União (LIMA, 2015, p. 48).

Diante desse grande cenário, as Cortes de Contas devem atuar indo muito além da mera fiscalização acerca da legalidade dos atos praticados pelos gestores públicos. As fiscalizações contábeis, financeiras, orçamentárias, operacionais e patrimoniais também precisam avaliar a legitimidade daqueles atos, isto é, deve-se investigar a necessidade e a relevância das ações de governo, bem como, se tais atos são éticos morais do ponto de vista social.

Nesse sentido, uma licitação realizada para aquisição de gêneros alimentícios para o Supremo Tribunal Federal, por exemplo, que esteja em conformidade com a lei, com as exigências normativas gerais e dentro dos limites orçamentários, será uma licitação válida quanto à sua legalidade. Mas se os alimentos adquiridos por meio dessa licitação forem, a título de exemplo, lagostas, vinhos e caviar, ela certamente não será uma licitação legítima, uma vez que a aquisição desses produtos não é necessária e indispensável ao atendimento do interesse público, tampouco se aproxima dos anseios da sociedade brasileira, tratando-se, na verdade, de um ato imoral quando comparado à situação financeira em que se encontra a grande maioria da população brasileira.

É justamente a esse cenário político imoral e incompatível com o interesse público que os Tribunais de Contas devem se opor, avaliando e julgando as contas públicas dos governos e das entidades com a finalidade última de se alcançar a maior eficiência da Administração Pública brasileira, não podendo se limitar à apreciação da legalidade, mas indo também ao alcance da legitimidade e da moralidade dos atos e, sobretudo, sem se contaminar com a politicagem desvirtuada inerente ao Poder Legislativo para o qual presta auxílio. 


\section{CONSIDERAÇõeS FINAIS}

Finalmente, é chegada a hora de analisar de forma conjunta e globalizante os principais assuntos dissertados neste trabalho, no intuito de se alcançar um juízo de valor conclusivo no tocante à importância que têm os Tribunais de Contas para a Administração Pública brasileira, assim como para a integridade da República e da democracia.

Antes de adentrarmos no mérito da discussão, convém esclarecer que temos plena consciência de que o desfecho deste trabalho certamente não será agradável aos comportados e pacíficos estudiosos, podendo, ainda, causar certa estranheza para alguns, mas nem por isso camuflaremos nossa real concepção sobre o assunto por de trás de eufemismos e abrandamentos, por mais peculiar e insurgente que seja a ideia aqui apresentada.

Assim, apreendidos os conhecimentos levantados ao longo do presente trabalho a respeito do que seriam as Cortes de Contas, suas características, funções e competências, especialmente no que tange às atividades exercidas para o auxílio do controle externo, e ainda, compreendido o contexto político em que estão inseridos esses Tribunais, passemos aos apontamentos que reputamos de maior relevância.

Como já apontado na primeira seção deste trabalho, as Cortes de Contas portuguesas e gregas possuem uma notória singularidade em relação às demais, haja vista que estão alocadas estruturalmente no âmbito do Poder Judiciário daqueles países, sendo, por esse motivo, os principais órgãos responsáveis pela fiscalização e julgamento dos atos administrativos realizados pelos seus governantes.

Essa realidade nos leva a questionar se a posição em que se encontram os Tribunais de Contas brasileiros constituiria, de fato, a mais coerente das estruturas constitucionais, posto que estão alocados como meros órgãos auxiliares do Poder Legislativo, limitados à simples fiscalização e emissão de pareceres sobre as contas de governo, enquanto que o julgamento, ato que concede efetiva responsabilização dos gestores pelas eventuais ingerências públicas, está incumbido ao Poder Legislativo, o qual, como já exposto, encontra-se entrelaçado com a obscura engrenagem das negociações parlamentares, as quais se mostram atoladas em meio aos interesses ideológicos, políticos e partidários.

Outro fato que deveria causar, no mínimo, indignação e repulsa na sociedade é a atual conjuntura que há muito já se tornou uma realidade no âmago do controle externo. Incontáveis procedimentos de fiscalização, dos mais diversos atos e contratos administrativos realizados pelos gestores públicos, após passarem por minuciosas análises técnicas e jurídicas dos Tribunais de Contas, cujos pareceres apontam inúmeras irregularidades e ilegalidades, são simplesmente ignorados pelas casas legislativas municipais, estaduais e federais quando dos julgamentos das contas que lhes são prestadas anualmente pelos Chefes do Poder Executivo, deixando que os administradores públicos saiam isentos de punição pelo mau uso do dinheiro público.

Além disso, não podemos deixar de mencionar aquilo que entendemos ser uma das maiores incoerências presentes no sistema de fiscalização que hoje vigora no país. A legislação pátria determina que os atos públicos empreendidos pelos jurisdicionados sejam, em sua expressiva maioria, levados à fiscalização somente após tornarem-se perfeitos e 
acabados, isto é, quando as eventuais irregularidades muitas vezes já teriam se tornado irreversíveis e irreparáveis, inclusive financeiramente.

Diante de tudo isso, concluímos, com audaciosa firmeza, que a eficiência da Administração Pública brasileira daria largos passos à frente de onde hoje se encontra, em direção ao melhor aproveitamento da coisa pública, se os Tribunais de Contas desta gigante nação detivessem a autonomia, a independência e as competências semelhantes às do Poder Judiciário brasileiro, para não apenas fiscalizarem e emitirem pareceres sobre as contas públicas, mas, sobretudo, para julgar e condenar administrativa, civil e penalmente os Chefes do Poder Executivo e todos aqueles que forem responsáveis por causar dano ao erário devido à má administração da coisa pública.

É dessa maneira que chegamos ao fim deste trabalho. Esperamos, sinceramente, ter alcançado os objetivos propostos inicialmente, e o mais importante de tudo, ter contribuído para o acervo de conhecimento dos doutos leitores e professores que nos deram a honra de apreciar as singelas ideias e proposições aqui apresentadas.

\section{REFERÊNCIAS}

ALBUQUERQUE, C. M. Gestão de finanças públicas: Fundamentos e práticas de planejamento, orçamento e administração financeira com responsabilidade fiscal, 2. ed. Brasília: Editora Gestão Pública, 2008.

ARISTOTLE, A. Política. Madrid: Alianza, 1986.

BARBOSA, R., Rui Barbosa: uma visão do controle do dinheiro público, TCU, 2000.

BRASIL. Decreto nº. 966-A, de 7 de novembro de 1890. Criou o Tribunal de Contas. Coleção de Leis do Brasil, p. 3.440, v. XI, 1890. Fascículo.

BRASIL. TRIBUNAL DE CONTAS DA UNIÃO. Rui Barbosa: Uma visão do controle do dinheiro público. Brasília: Tribunal de Contas da União, 2000.

BRASIL. SUPREMO TRIBUNAL FEDERAL. Ação Direta de Inconstitucionalidade ${ }^{\circ}$. 4.190. Brasília: Ementário 2405-2, 2010. Disponível em: http://redir.stf.jus.br/paginadorpub/paginador.jsp?docTP=AC\&docID=612217. Acesso em: 19 out. 2020.

BRASIL. Constituição da República Federativa do Brasil: promulgada em 5 de outubro de 1988. São Paulo: Saraiva, 2012.

BRASIL. CÂMARA DOS DEPUTADOS. Gastos parlamentares, 2020. Disponível em: https:/www.camara.leg.br/transparencia/gastos-parlamentares/. Acesso em: 19 out. 2020.

CAGGIANO, M. H. S. Direito parlamentar e direito eleitoral. Barueri, SP: Manole, 2004. 
CARNEIRO, M. F. S. Gestão Pública: O papel do planejamento estratégico, gerenciamento do portfólio, programas e projetos e dos escritórios de projetos na modernização da gestão pública. Rio de Janeiro: Brasport, 2010.

CASTARDO, H. F. O Tribunal de Contas no ordenamento jurídico brasileiro. Campinas, SP: Millenium, 2007.

EXPOENTES NA HISTÓRIA DO BRASIL. Uma breve história do controle: na visão de um Tribunal centenário. Belém, 1932. Disponível em: <https://www.tce.ba.gov.br/files/flippingbook/livro_de_ouro/files/assets/basic-html/page44.html >. Acesso em: 23 jun. 2020.

FERREIRA FILHO, M. G. O poder e seu controle. Revista de Informação Legislativa. Ano 21, n. 84. Brasília: out./dez., 1984.

GUERRA, E. M. Controle externo da Administração Pública, 4. ed. Belo Horizonte: Fórum, 2019.

LENZA, P. Direito constitucional esquematizado, 19. ed. rev., atual. e ampl. São Paulo: Saraiva, 2015.

LIMA, L. H. Controle externo: teoria e jurisprudência para os tribunais de contas, 7. ed. rev. e atual. Rio de Janeiro: Forense; São Paulo: Método, 2015.

LOCKE, John. Segundo tratado sobre o governo. São Paulo: Martin Claret, 2002.

MARTELLO, A. Dívida pública sobe quase R\$ 200 bi em 2010, maior aumento desde 2001. Brasília: Globo, 2011. Disponível em: Disponível em: http://g1.globo.com/econo$\mathrm{mia} /$ noticia/2011/02/divida-publica-sobe-quase-r-200-bi-em-2010-maior-aumento-desde-2001.html. Acesso em: 19 de out. 2020.

MEIRELLES, H. L. Direito administrativo brasileiro / Hely Lopes Meirelles, José Emmanuel Burle Filho, 42. ed. / atual. até a Emenda Constitucional 90, de 15.9.2015. São Paulo: Malheiros, 2016.

MONTESQUIEU, C. de S. B. de. O espírito das leis. São Paulo: Martins Fontes, 1996.

PORTUGAL. ASSEMBLEIA DA REPÚBLICA. Constituição da República Portuguesa, 2005. Disponível em: https://www.igac.gov.pt/documents/20178/358682/Constitui\%C3\%A7\%C3\%A3o+da+Rep\%C3\%BAblica+Portuguesa.pdf/75cbb3ef-b379-43a3-af8c-78ff82b1868f. Acesso em: 19 out. 2020.

ZYMLER, B. Direito Administrativo e controle, 3. ed. Belo Horizonte: Fórum, 2012. 


\section{DADOS DOS AUTORES}

\section{Guilherme Aparecido da Silva Maia}

Graduado em Direito, especialista em Inovação e Difusão de Tecnologias, Mestre e Doutor em Meio Ambiente e Desenvolvimento Regional, na linha de pesquisa sobre Proteção Jurídica do Conhecimento (Propriedade Intelectual e Direitos de Autor). professorguilhermemaia@gmail.com

\section{Diego Schlosser de Sá Teles}

Bacharel em Direito pela Faculdade Estácio de Sá. diegoteles@live.com

Submetido em: $24-6-2020$

Aceito em: 20-10-2020 